\title{
The Challenge of Overcoming Schizophrenia and a True Vision for the Future
}

\author{
Sukanchan Palit* \\ University of Petroleum and Energy Studies, Dehradun, Uttarakhand, India
}

\begin{abstract}
Schizophrenia is devastating ailment. There is no end to the agony and pain behind the illness. As a schizophrenic, I am keen to write a deeply comprehensive treatise on this ailment which destroyed my life. At each step of human progress, schizophrenia devastates the future vision of a human being. This is an extremely poignant article which will touch teeming millions of sufferers throughout the world. The cause, progress and the present status of my health is delineated in lucid details. It was a disastrous start of my illness. Confusion and hallucination reigned high in the midst of tremendous uncertainties. But medication with Clozapine and psychological counseling pulled me out of the catastrophe. Schizophrenia is an unending agony in my life. The vision of this treatise is to create a far-reaching awareness about the cause, progress of recovery and the ultimate vision of medicinal counseling. Advancement of science and technology, the arduous path of scientific progress and the tremendous progression of the ailment of schizophrenia will go a long way in the true emancipation of freedom from an irreversible illness and the true scientific truth. The author goes at length on the topic of the crisis of health issues, the progress of recovery and the final and true emancipation of medical science. Medical science is moving from one visionary avenue over another. The message of this treatise is towards the silent sufferers. The wide vision, the utmost targets and the process of recovery will surely open up new dimensions of hope for the silent sufferers in years to come. The message to the silent sufferers are vast and visionary. The author also with deep and intricate insight deals with the subject of neuropsychiatry relating to his illness. The wide vision is unparalleled and unimaginable. The world of challenges the author had to face is delineated with agonizing details.
\end{abstract}

Keywords: Schizophrenia; Illness; Vision; Clozapine; Recovery

\section{Introduction}

The agony of a schizophrenic patient is unimaginable. I am a patient of schizophrenia from 1993. Advancements in science and technology, the progress of medical science and the unending quest in medical science for recovery has urged the scientific domain to ponder towards giant strides in medical history. The author with lucid details uncovers the intricate details of the cause and effects of the dangerous ailment of schizophrenia. The path to recovery for a sufferer is immense and scientifically unjustified. Yet the world of challenges, the immense grit and determination has made my life more easier. The medical science of schizophrenia is inspiring to the doctors and scientists and has opened a world of innovation and scientific research pursuit. The challenge, the enigma and the progress of the illness has opened a new world of scientific vision and scientific fortitude. Defeat is a definition at every step of a sufferer's life yet the positive mental state of mind has urged the schizophrenic to gear for more challenge and vision ahead. Till today, the cause of the illness is unknown and devastating yet medical science is creating absolute wonders and immense definitive vision. The author with poignant touch and incisive innovation delves deep into his life, its bitter fate and the world of unimaginable challenges and defeats $[1,2]$.

\section{Vision of the present treatise}

Vision, aim and mission of the study are wide, versatile and many. The author, with strong inner vision, relates the every step of his life and his ailment. The agonizing days are delineated in details. It was in the month of June, 1993, I was confused, derailed and in a wayward direction. My life changed towards a devastating direction. I am a postgraduate in Chemical Engineering from Jadavpur University, Kolkata, India. I graduated in December, 1992 and soon took admission to the postgraduate course in the same university in 1992. It was one and a half Masters of Engineering course. We had to take coursework and a project supervised by a Faculty from my Department of Chemical Engineering. From those days of agony and confusion, the author tries to retrace history. The history of the illness of schizophrenia and the history of my agony just culminated after graduation due to lack of employment opportunities. The vision of life became stunted and a new course of illness ridden path ushered in. This treatise delineates with deep concern the agony and pain of the sufferers of schizophrenia. Water has flowed much in the river since my first diagnosis and the agony of life trebled. Yet till today I am not free from this death defying ailment. The present status of my illness is still simmering yet the positive state of mind has pushed my conscience to move further. The vision and aim of the treatise lucidly relates the immense importance of medication and psychological counseling. The answers to the progress of recovery are latent yet visionary. Vision of medical science has opened up new avenues of relief and recovery with an eye on research [1,2].

\section{The enigma of the ailment}

The enigma of the ailment opens one mind's door over another. Scientific achievements, the urge to excel and the positive state of mind are the forerunners of a deeper thought about schizophrenia. I have

*Corresponding author: Sukanchan Palit, University of Petroleum and Energy Studies, Dehradun 43, Judges Bagan, Post Office- Haridevpur, Kolkata-700 082, India, Tel: +918958728093/+913324026947; E-mail: sukanchan68@gmail.com/ sukanchan92@gmail.com

Received September 16, 2015; Accepted November 05, 2015; Published November 11, 2015

Citation: Palit S (2015) The Challenge of Overcoming Schizophrenia and a True Vision for the Future. Neurochem Neuropharm Open Access 1: 104.

Copyright: (C) 2015 Palit S. This is an open-access article distributed under the terms of the Creative Commons Attribution License, which permits unrestricted use, distribution, and reproduction in any medium, provided the original author and source are credited. 
faced frustration and agony in every step of life from November, 1993. Till today the weird world of persecution and recurrent hallucination haunts me. The journey is never ending. The world is so full of challenges for me. It is my deep and comprehensive message to the silent sufferers that a positive state of mind is the winner of the day. Deep praying to the God Almighty to give me strength, fortitude and forbearance will one day open my doors of the ensconced mind. The illness of schizophrenia can only be overcome and defeated if strong psychological counseling can addressed and rebuilt. History of schizophrenia, the world of difficulties, the catastrophes and the urge to excel will one day bring me out of the recurrent disasters [3].

\section{The beginning years of my illness}

The initial years of my illness were bleak and in the same way painful. Every step of my life had unmitigated disaster. Just after graduation in Chemical Engineering from Jadavpur University, Kolkata, India, my nervousness, confusion and self-doubt accumulated in my mind. Nervousness and anxiety took over my life. I was too nervous to start a new career in advanced Chemical Engineering. I did not get that much of support from my teachers, friends and relatives in those initial days. It was in sweltering month of June, 1993, I started my project work under two eminent teachers of the University. In such a critical juncture, my mind started becoming wayward. History of my illness took a disastrous direction. Mind's torture evolved. I was too nervous to talk to my batch mates and friends in those initial years. From the final year of my graduation I started becoming introvert. Today with retrospection, I can add that my being introvert was ingrained in my mind. That may be the plausible cause of my illness. Confidence of mind and body was shattered. Slowly I was doing my project work in the summer and fall of 1993. In such a critical phase of mind, I started taking medicines without prescription. It seemed soothing to me. My parents and sister were unaware of my illness during that period. Suddenly one December winter night I was bedraggled and visited my teacher's house at $1 \mathrm{AM}$ at night. I started thinking of a diary which contained classified information. Black magic took over my mind. Illness multiplied at every step of life. My personal conscience became devastated. My struggle ensued. Suddenly I was rushed to a psychiatrist with immense agony of my parents. My mother shed her tears with shattering agony of her mind also. Sometimes she cried out to God to bring her son back to life. Inspite of the shattered mind, I completed my post-graduation in March, 1994 and joined a job in New Delhi, India in April, 1994 [1,2]. Peace and harmony reverted back as I faced new atmosphere in an office in New Delhi [3]. But I started discontinuing medicines prescribed by my doctor in Kolkata, my hometown. Disasters and devastation became the order of the day [3]. Peace and harmony of life became unsettled. I was working in a reputed multinational company in New Delhi but I stopped taking medicines. It was the final and true disaster in my life. Disharmony of mind made my life to a paranoid schizophrenic. I worked there up to August, 1994 after which I shifted to Kolkata to a new industrial engineering job. My life fell down like a house of cards. At Kolkata, my illness started to deteriorate. I was consulted with numerous psychiatrists and psychologists. But my immense grit and determination pulled me out of the unmitigated agony. Advancement of medical science has no answer. In my job, I was told to go on an outdoor job to a paper mill in Madhya Pradesh, India. My self-confidence, self-conscience and vision to excel in life were shattered. Soon I also changed my doctors. It was also a devastating challenge in my life. The Almighty and the Supreme Power had no answers to my repeated prayers. Advancement in science, medical breakthroughs and the challenges within me are the torchbearers to a new future dimension. I always tried to tell myself that one day I will win and excel in life. Job pressures devastated me. I was infrequent with my medicines. Yet my challenge and grit urged me to move forward. In September, 1996, I got a job of a Faculty of Chemical Engineering at one of the most reputed universities in North India. My disaster trebled [3].

\section{Immense agony and the unmitigated pain}

Agony, pain and hallucination of life are part of my life [3]. Mental derailment in life has today derailed my path of life. Anxiety is a cause of my inefficiency in job. Yet the urge to excel and the power to surge forward in life have been a torchbearer as well as a virtual forerunner in life. Man's vision, mankind's social prowess and the immense grit and fortitude of life has helped me in overcoming one obstacle over another in life. Hallucination is an ornament in my life. Lack of self-confidence, the utter disbelief and the immense uncertainties has given my life a stunted vision. The deluge of agony is unimaginable. History of mankind has never witnessed such kind of painful and agonizing illness. Medical science is at a trance and challenge. The challenge to schizophrenia today is to readdress the science of psychological counseling. The barriers and difficulties of science are awe-inspiring. Scientific advancements, the society's progress and the torchbearers of science will go a long way in the true emancipation of medical science. Society will never uplift schizophrenia. The awareness of compassion needs to be rebuilt and rethought. Today I am substantially cured. But the agony of future will surely awaken the scientific horizon. Man's thoughts, a patient's cure and the age-old wrong beliefs will one day open a new awakening and a new horizon. Patience, fortitude and compassion are the coin words of the future of recovery from schizophrenia. The challenge and fortitude lies in the hands of the sufferer and his parents. Till today the parents are beside me. From the beginning of the disastrous days of agony my parents, sister and relatives were by my side. Society generally never accepts a schizophrenic. In the midst of agony, I also faced similar problems. I worked in research, teaching and industry which are specialized branches of scientific endeavor. Yet I faltered sometimes in the midst of burden of the ailment. Today, at the end of the day, sometimes I feel like giving up. Yet the grit and the urge to do something in life pushed me forward. History is today repeating itself $[1,2]$. I fear of relapse at each step of life. The battle, the urge and the goals to move forward pushes me towards a newer vision $[3,4]$.

\section{The recurrent relapses and the hapless hopes}

The battle against schizophrenia and the wonders of science of psychiatry are endless. The glitter and glory of life is blurred and the vision stunted. Till today I fear of relapses and recurrent hallucinations. I work in a highly professional and specialized atmosphere in a university. I call Almighty God to make me free from my ailments [3]. I am taking the medicine - Clozapine from 1997. Today my glory and forbearance in life is due to the help of my doctors and parents. My sister also helped me a lot from the first days of my illness. During that period in life, my life stalled and is occupied with immense delusions. Life was immensely negative to me. Only courage, determination and the willpower made me stronger day by day [3]. As I had written earlier, Clozapine helped me a lot. It was first administered throughout the world in 1997 at the same time I was also prescribed by my doctor at Kolkata and National Institute of Mental Health and Neuro Sciences (NIMHANS), Bangalore, India. I visited with my parents to NIMHANS, Bangalore twice to adjust my medication. This is how my medication with Clozapine started. After that year, I was jobless. I had to haplessly work in a factory of my relative. The joy of working hard gave way to agony. Clozapine became a lifesaving drug for me. In 1996, I truly recovered slowly. I worked as a Content Developer in Mathematics in 
two companies. Then, in September, 2008, I went to Queen's University, Belfast, Northern Ireland, UK in a one and half year research project. I surely enjoyed doing research work inspite of my illness. Then in May, 2010 I returned to India to work in an engineering college in Karnataka, India. I really enjoyed teaching Chemical Engineering which is my forte [3]. After that again I went for 8 months to Oman on a teaching assignment. From July, 2012, I am working as an Assistant Professor of Chemical Engineering at a reputed university of North India. The courage surpassed many visionary boundaries. Today I am more courageous and steady. The fear and nervousness is still prevalent but the avenues of recovery and fortitude are many. The positive state of mind has become my torchbearer $[3,4]$. Hope, courage and immense willpower pushed me forward in my way towards recovery. Today I have glaucoma in my both eyes, irritable bowel syndrome and osteo-arthritis. Yet I am a winner in life. Sometimes I feel hapless and dejected in life. The happiness, joy and ecstasy have no definite answers in my life. The world of challenges has always been painful and depressive to my life. History of human mankind and history of medical science is so stunted with each passage of time and life. There are still no answers to the cure and recovery of schizophrenia. From a hapless child, I have grown up to a man and professional inspite of my difficulties. Sometimes I call to Almighty God to give me some alms and some mental gifts. Yet God sometimes does not look at me. This is the fate of my life and the fate of a schizophrenic. The joy and ecstasy gave in place to immense agony at each step of a sufferer's progress.

\section{Future of the medical world of schizophrenia}

Future medical scenario of schizophrenia is visionary and farreaching. A normal person cannot comtemplate what agony one has to pass through with the progress of the illness. Defeat, disaster and excruciating mental pain has become a way of my painful life. The only decisive target to the sufferers is that one should not lose any hope and one should have an extremely positive state of mind. It will not develop in one day. It will continue for years along with medical attention and counseling. Schizophrenia will surely be erased as a difficult ailment if strong willpower in a patient will rejustify the scientific and future medical vision. Schizophrenia in today's world can be cured with immense self-confidence and self-realization. These concepts will never cultivate in a day. It will take years to bring in the self-confidence. The wonders of science and medicine are at the backbone of the silent sufferers of schizophrenia [3]. Man's vision, a technological prowess and scientific vision will one day surely bring relief to the weary schizophrenic patient. The question arises as to how medical science can bring a new scientific vision. It is the strong psychological counseling which is the backbone of progress and the winner of the day. In today's world mental depression can be cured with utmost care and immense compassion. The main target of the counselor is to understand the sufferer's mind. If that action is taken into account, the world will surely a wonderful place to live in for a schizophrenic patient. I have grappled severely schizophrenia for two decades. I encountered so many barriers and difficulties. Yet today I am strong due to my strong grit and determination. This shows that the world of challenges and difficulties can be veritably won over if a schizophrenic can inculcate self-confidence and immense grit $[3,4]$.

\section{Recovery, vision and courage to encounter schizophrenia}

Recovery from schizophrenia is slow [3]. The vision and aim in life should be intact. The wonders of medical science are by the side of a patient. I suffered loneliness yet I have an inner thought that my parents and Almighty God are by the side of me everywhere where I am. This memoir is a scientifically visionary document of my illness.
Medical science in today's world is surpassing visionary frontiers. Care, compassion and courage are the winners of the day. Today's realization is tomorrow's vision. In today's world the anatomy of life and progress of human life is changing. Man's willpower is minnowed at every step of illness. In such a crucial juxtaposition, history of medical science needs to be rebuilt and reshaped. The courage and positive state of mind will be the torchbearers of future. Challenges, vision and urge to excel will surely be the winners at the end of the day. In my life, history repeats itself at every step of future. I am still today not free from schizophrenia. Yet the immense courage and God's forbearance is pushing and goading me forward [4].

\section{Conclusion}

Schizophrenia can never be recovered in a patient. It is a crucial juxtaposition of mankind's struggle and the visionary progress of life. I am a schizophrenic for the last 21 years. Only strong determination and immense courage has brought back my lost life. Advancement of science, the history of grit and the immense will power has pushed me through the avenue of life. The power and urge to excel has removed all my agonizing tears. So, today my only message to the sufferers is the willpower to win over indomitable challenges. In its truest sense schizophrenia can be defeated. Man's prowess, courage to win and the inculcation of indomitable courage will one day open the closed doors of a sufferer's mind. Only at that juncture, the illness can be defeated and the true ecstasy will open up windows of relief $[3,4]$.

\section{References}

1. Weiner SK (2003) First Person Account: Living with the delusions and effects of Schizophrenia. Schizophrenia Bulletin 29: 877-879.

2. Woods A (2013) Rethinking "Patient Testimony" in the Medical Humanities: The case of Schizophrenia Bulletin's First Person Accounts. Journal of Literature and Science 6: 30-54.

3. Sukanchan Palit (2014) Schizophrenia and vision of my life. First Person Account. Schizophrenia Bulletin, Oxford University Press, USA.

4. Sukanchan Palit (2015) The struggle and vision of my life-A memoir, Recovery from Schizophrenia and a deep comprehension. Notion Press, Chennai, India. 